\title{
A female with dry cough, progressive dyspnoea and weight loss
}

\author{
C.B.E. Chee*, J.L. Da Costa ${ }^{\#}$ and C.S. Sim
}

\section{CASE HISTORY}

A 43-yr-old Chinese female presented with dry cough, weight loss of $2 \mathrm{~kg}$, and progressive breathlessness of 1 month duration. Her symptoms progressed despite two courses of oral antibiotics (a macrolide and a $\beta$-lactam) and traditional Chinese medication. There was no fever, wheeze, haemoptysis or chest discomfort. She was a life-long nonsmoker and worked in an office environment with no known exposures to chemicals, fumes or dust. She had not travelled out of

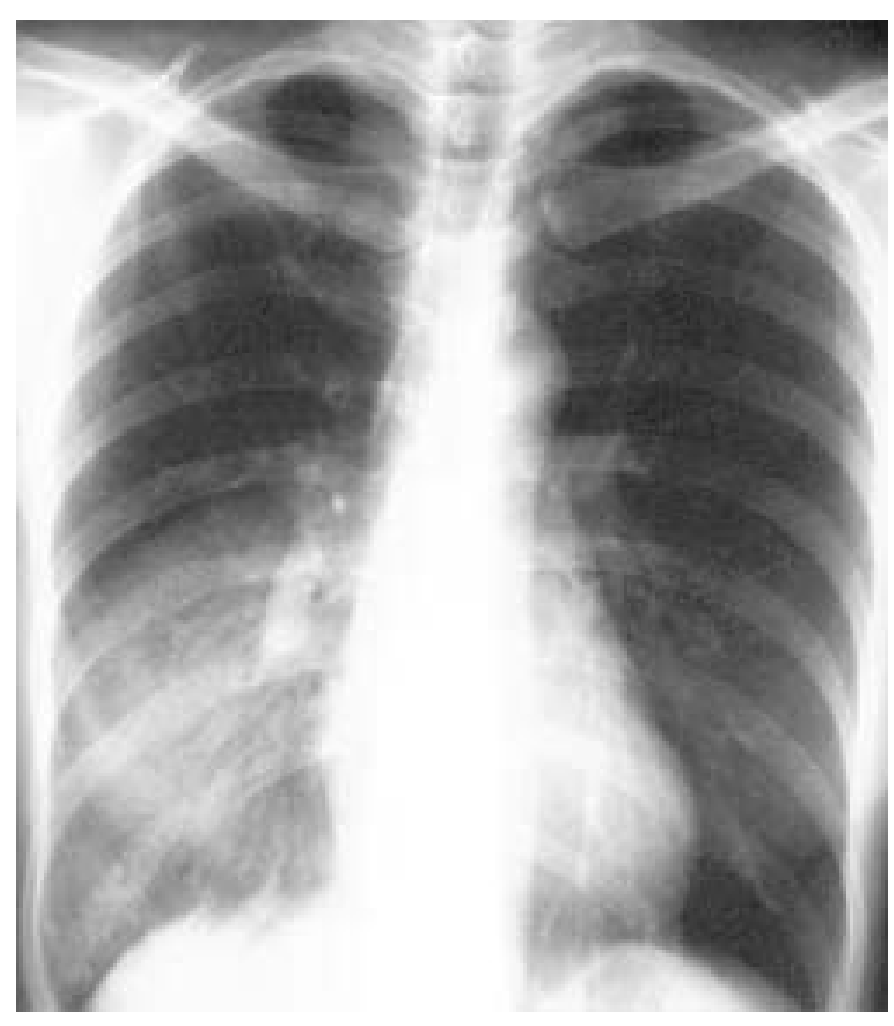

FIGURE 1. Posteroanterior chest radiograph at initial presentation.
Singapore for 1 yr. The only past medical history of note was that of mild asthma, which had been in remission for 10 yrs.

On physical examination, there was no fever, clubbing, skin lesions, cervical lymphadenopathy or joint swelling. Auscultation of the lungs revealed crepitations with diminished breath sounds over the posterior right chest. Cardiovascular, abdominal and neurological system examinations were unremarkable.

The initial chest radiograph (fig. 1) and computerised tomographic (CT) scan of the thorax (fig. 2) are as shown. Full blood count on three separate days showed normal total white cell count and normal differential count. The erythrocyte sedimentation rate was $75 \mathrm{~mm} \cdot \mathrm{h}^{-1}$. The renal function was normal. The tuberculin skin test was negative. Fine needle aspiration of the lung lesion was performed 4 days after presentation and this was reported as "suggestive of organising pneumonia".

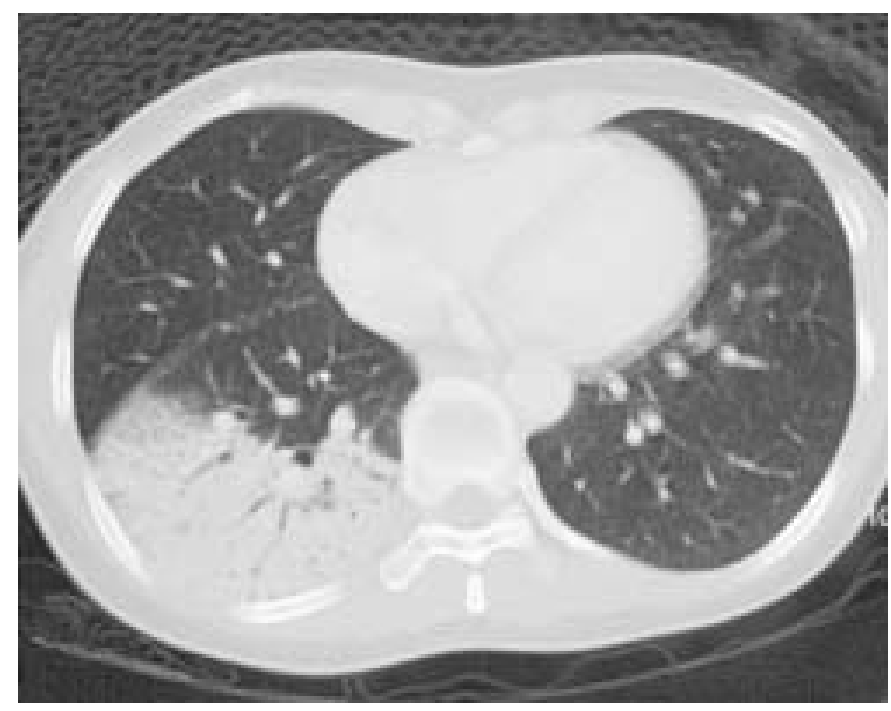

FIGURE 2. Computed tomography of the chest, parenchymal window, at initial presentation.

\footnotetext{
*Dept of Respiratory Medicine, Tan Tock Seng Hospital, "Chew, Da Costa Pte Ltd, and "Parkway Laboratory Services Ltd, Mount Elizabeth Hospital, Singapore. Correspondence: C.B.E. Chee, Dept of Respiratory Medicine, Tan Tock Seng Hospital, 11 Jalan Tan Tock Seng, Singapore 308433. Fax: 65 63577871. E-mail: cynthia_chee@ttsh.com.sg
} 


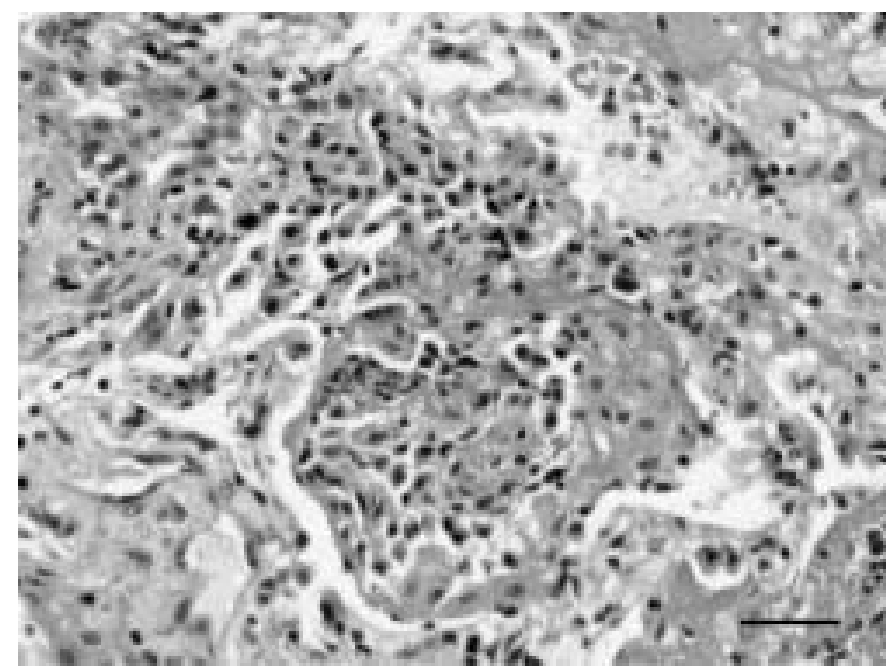

FIGURE 3. Histological picture of video-assisted open lung biopsy specimen. Haematoxylin and eosin stain. Scale bar $=160 \mu \mathrm{m}$.

Bronchoscopy did not reveal any endobronchial lesion. As the treating physician felt that it was important to exclude malignancy, video-assisted thoracoscopic (VATS) open lung biopsy from several sites of the right lower lobe (fig. 3) was performed 6 days after presentation. There was no bacterial growth detected from cultures of the lung aspirate, lung tissue or blood.

The patient appeared to respond to i.v. ceftazidime, oral ciprofloxacin and fluconazole in the first 5 days after the VATS biopsy; however, her condition then deteriorated and she was

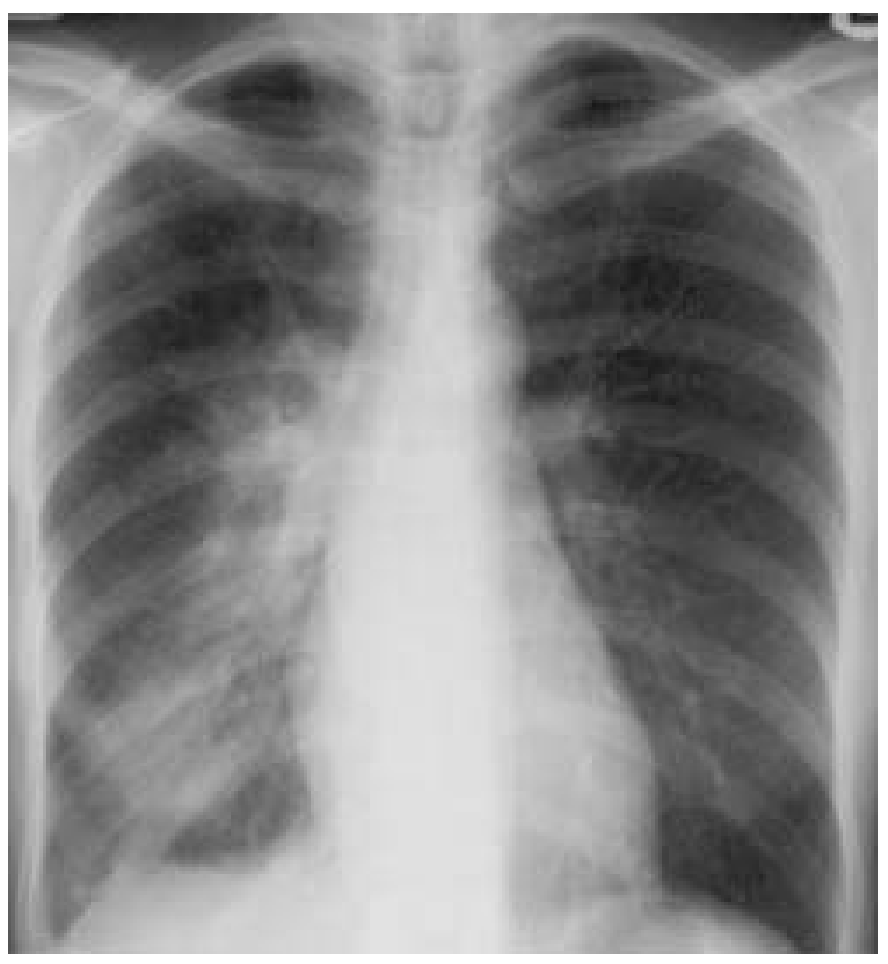

FIGURE 4. Posteroanterior chest radiograph, 18 days after initial presentation.

referred to the present centre for management. At this point, she required supplemental oxygen to maintain her oxygen saturation. Her chest radiograph at this time is shown in figure 4 .

\section{BEFORE TURNING THE PAGE, INTERPRET THE ROENTGENOGRAMS AND BIOPSY AND SUGGEST A DIAGNOSIS.}




\section{INTERPRETATION \\ Chest radiograph}

The initial chest radiograph showed an opacity in the distribution of the right lower lobe (fig. 1).

\section{Computed tomographic scan}

CT scan of the thorax (fig. 2) performed on the same day as the chest radiograph of figure 1 showed consolidation in the posterior segment and apical segment of the right lower lobe. There was no mediastinal lymphadenopathy or pleural effusion.

\section{Histological picture}

The specimen from the right lung showed preservation of the lung architecture with diffuse intra-alveolar exudate of granular, fibrinous material with patchy aggregates of polymorphs and microscopic foci of foamy alveolar macrophages (fig. 3). Type II pneumocyte hyperplasia and interstitial fibrosis were noted. No acid-fast bacilli or fungi were seen.

\section{Chest radiograph}

This showed progression of the right-sided opacity to involve the right peri-hilar region, with development of a right-sided pleural effusion (fig. 4).

Diagnosis: Cryptogenic organising pneumonia (COP).

\section{TREATMENT AND CLINICAL COURSE}

Oral corticosteroid (prednisolone $1 \mathrm{mg} \cdot \mathrm{kg}^{-1} \cdot \mathrm{day}^{-1}$ ) alone was commenced with dramatic symptomatic improvement after

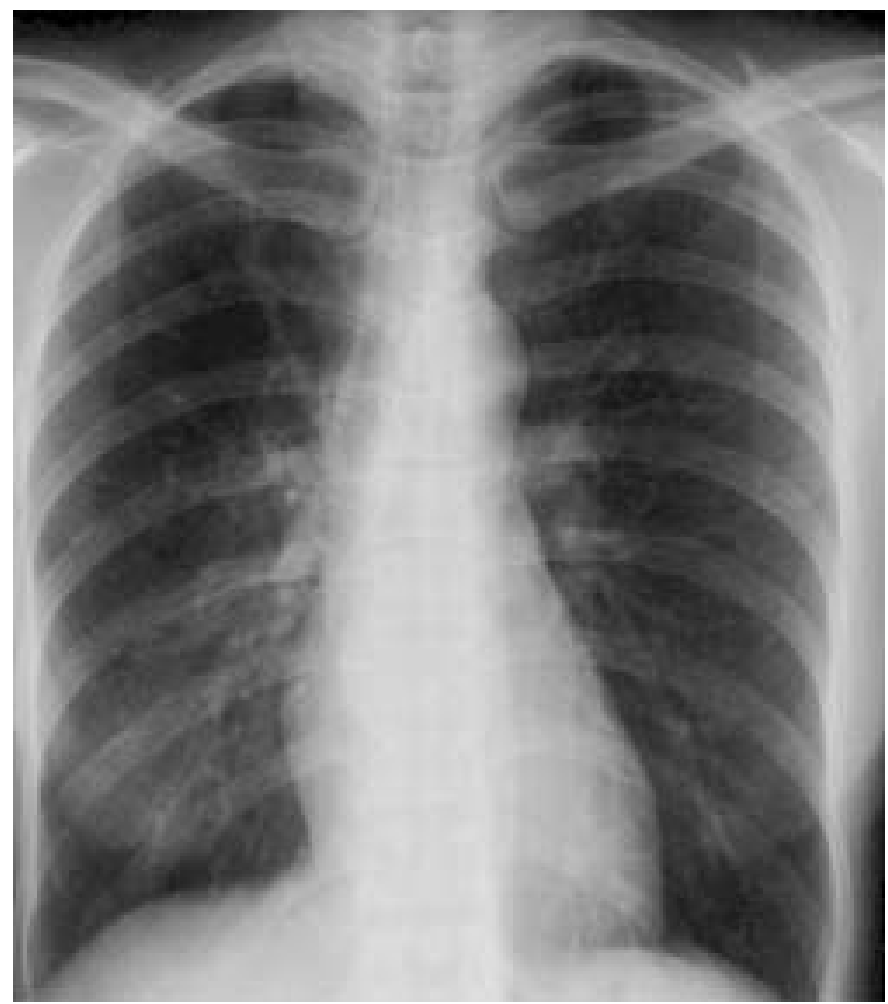

FIGURE 5. Posteroanterior chest radiograph, 6 days after commencement of corticosteroid therapy.
$24 \mathrm{~h}$ and a near-complete clearing of the radiograph infiltrates by the sixth day of treatment (fig. 5). She remained well and her chest radiograph was normal at 3 months of treatment, while on a tapering dose of prednisolone.

\section{DISCUSSION}

COP was first described in 1983 by DAvISON et al. [1], and subsequently in 1985 by EPLER et al. [2] as bronchiolitis obliterans with organising pneumonia (BOOP). This clinicopathologic entity is characterised by histological findings of polypoid masses of granulation tissue in the lumens of small airways, alveolar ducts, and alveoli. COP is the preferred term, as organising pneumonia is the major histological criterion, and bronchiolitis obliterans may be absent in some cases. This term, unlike BOOP, would also avoid confusion with airway diseases, such as constrictive bronchiolitis obliterans. The histological pattern of "organising pneumonia" may be idiopathic or associated with drug reactions, infections, collagen vascular disease, malignancies or radiation therapy. The most common chest radiograph abnormalities are those of diffuse, patchy, ground glass or alveolar densities. This disease usually runs a benign course, with complete clinical, physiological and radiographic response to corticosteroid therapy in most patients.

Besides the characteristic finding of multiple, patchy alveolar opacities with a peripheral and bilateral distribution that may be migratory, other radiographic manifestations of COP include diffuse bilateral infiltration associated with interstitial opacities. More rarely, solitary focal or pneumonic lesions, or cavitary lesions have also been described in COP [3-5]. Bilateral radiographic opacities were seen in all the cases reported in a Canadian series of 11 patients [6], and a Japanese series of 34 patients [7]. In another series of 37 patients with COP, eight patients $(22 \%)$ had unifocal region of consolidation or mass [8]. No further details of the localisation or nature of the lesions in these patients were provided.

The patient's clinical presentation in the current study of subacute onset of cough and dyspnoea, and her rapid response to corticosteroid therapy were typical of COP. There was no evidence of infection or malignancy; nor of other factors known to be associated with the histological pattern of organising pneumonia (e.g. collagen vascular disease, eosinophlic lung disease, drug reaction) present in the patient.

Unilateral lobar consolidation is an infrequent radiographic finding in cryptogenic organising pneumonia. As such, this diagnosis was initially not suspected in the present patient, and the more common causes of unilobar consolidation, such as bacterial pneumonia or malignancy, were first considered. This case study illustrates an unusual radiographic manifestation of cryptogenic organising pneumonia. This diagnosis should also be considered in patients with nonresolving unilateral lobar consolidation in whom infective and neoplastic diseases have been excluded.

\section{REFERENCES}

1 Davison AG, Heard BE, McAllister WAC, TurnerWarwick ME. Cryptogenic organizing pneumonitis. Q J Med 1983; 207: 382-394. 
2 Epler GR, Colby TV, McLoud TC, Carrington CB, Gaensler EA. Bronchiolitis obliterans with organizing pneumonia. N Engl J Med 1985; 312: 152-158.

3 Cordier JF. Organizing pneumonia. Thorax 2000; 55: 318-328.

4 Cordier JF, Loire R, Brune J. Idiopathic bronchiolitis obliterans organizing pneumonia. Chest 1989; 96: 999-1004.

5 Cordier JF. Cavitary bronchiolitis obliterans organizing pneumonia. Eur Respir J 1995; 8: 1822-1823.

6 Guerry-Force ML, Muller NL, Wright JL, et al. A comparison of bronchiolitis obliterans with organizing pneumonia, usual interstitial pneumonia, and small airways disease. Am Rev Respir Dis 1987; 135: 705712.

7 Izumi T, Kitaichi M, Nishimura K, et al. Idiopathic bronchiolitis obliterans organizing pneumonia with peripheral infiltrates on chest roentgenogram. Chest 1992; 102: 715-719.

8 Lohr RH, Boland BJ, Douglas WW, et al. Organizing pneumonia. Features and prognosis of cryptogenic, secondary and focal variants. Arch Intern Med 1997; 157: 1323-1329. 